\title{
Beyond tumorigenesis: cancer stem cells in metastasis
}

\author{
Feng $\mathrm{Li}^{1,{ }^{*}}$, Benjamin Tiede ${ }^{1, *}$, Joan Massagué ${ }^{2}$, Yibin Kang ${ }^{1}$ \\ ${ }^{I}$ Department of Molecular Biology, Princeton University, Washington Road, Princeton, NJ 08544, USA; ${ }^{2}$ Cancer Biology and Genetics \\ Program and Howard Hughes Medical Institute, Memorial Sloan-Kettering Cancer Center, New York, NY 10021, USA
}

The importance of cancer stem cells (CSCs) in tumor-initiation has been firmly established in leukemia and recently reported for a variety of solid tumors. However, the role of CSCs in multistage cancer progression, particularly with respect to metastasis, has not been well-defined. Cancer metastasis requires the seeding and successful colonization of specialized CSCs at distant organs. The biology of normal stem cells and CSCs share remarkable similarities and may have important implications when applied to the study of cancer metastasis. Furthermore, overlapping sets of molecules and pathways have recently been identified to regulate both stem cell migration and cancer metastasis. These molecules constitute a complex network of cellular interactions that facilitate both the initiation of the pre-metastasis niche by the primary tumor and the formation of a nurturing organ microenvironment for migrating CSCs. In this review, we surveyed the recent advances in this dynamic field and propose a unified model of cancer progression in which CSCs assume a central role in both tumorigenesis and metastasis. Better understanding of CSCs as a fundamental component of the metastatic cascade will lead to novel therapeutic strategies against metastatic cancer.

Cell Research (2007) 17:3-14. doi:10.1038/sj.cr.7310118; published online 19 December 2006

Keywords: stem cells, cancer stem cells, metastasis, metastasis niche, mouse model

\section{Introduction}

Metastasis, the spread of cancer cells from primary tumor sites to distant organs and tissues, accounts for over $90 \%$ of lethality in cancer patients [1]. In spite of its clinical importance, the underlying cellular and molecular mechanisms of cancer metastasis are still poorly understood. In recent years, stem cells have been the focus of a tremendous amount of biomedical research because of their apparent potential for regenerative medicine. The discovery of cancer stem cells (CSCs) has stimulated great excitement, as well as heated debates, for both stem cell and cancer biologists. How the CSC theory fits into the general scheme of cancer progression, particularly with respect to metastasis, has not been well-defined. This review begins by comparing some characteristic features of normal and malignant stem

*These two authors contributed equally to this work Correspondence: Yibin Kang

Tel: +1-609-258-8834; Fax: +1-609-258-2340;

E-mail: ykang@princeton.edu cells that are highly relevant to cancer metastasis. These attributes lead us to propose that the ability of a tumor to metastasize is an inherent property of a subset of CSCs, coined here as metastatic CSCs (mCSCs). This ability is modulated through the interactions of the mCSCs with the local microenvironment or "niche". Guided by current knowledge about normal stem cells, future characterizations of the origin, as well as the cellular and molecular mechanisms governing the in vivo behaviors of mCSCs, should shed light on potential therapeutic applications related to metastasis. Before proceeding, however, it is important to keep in mind that various aspects of the CSC theory remain to be unequivocally confirmed in different cancer types, particularly in solid tumors [2]. Therefore, this review should be considered as a discussion of the current status of the field and as a guide for future research rather than summaries of proven hypotheses.

\section{Normal stem cells}

Two golden standards for defining normal stem cells were first established from studies of hematopoiesis [3]. 
In order to sustain a lifelong supply of blood cells, hematopoietic stem cells (HSCs) must have the ability to (1) self-renew and (2) generate differentiated blood cells. In addition to the well-characterized HSCs, adult stem cells have also been found in a variety of tissues and organs including muscle, intestine, brain, skin/hair follicles, heart, lung and, more recently, mammary glands [4-8]. The physiological function of normal stem cells is to maintain tissue homeostasis as well as to regenerate tissue after damage or injury. Prospective isolation of normal adult stem cells such as HSCs, neural stem cells and mammary epithelial stem cells (MESCs) has been accomplished by using combinations of cellular phenotypic markers (summarized in Table 1). Additionally, isolating a "side population" based on Hoechst33342 dye efflux (due to high activity of cell membrane multi-drug transporters) has been used as an alternative way of identifying stem cells [9].

As exemplified by HSCs, under normal physiological conditions, adult stem cells can live in a prolonged state of quiescence. Cell cycle regulators $\mathrm{p} 21^{\mathrm{CIP} 1}$ and $\mathrm{p} 18^{\mathrm{INK} 4 \mathrm{C}}$ have been shown to regulate the quiescence of HSCs $[10$, 11]. Once they have exited from the quiescent state, stem cells either self-renew or differentiate to generate progenies depending on the nature of both intrinsic and extrinsic stimulatory signals $[3,12,13]$. These signals exist as a delicate "Yin \& Yang" balance between positive and negative regulators. Using genetic models, key factors of the Wnt signaling pathway have been shown to be essential for promoting stem cell self-renewal in various systems [14-20]. Notch and hedgehog signaling pathways have also been demonstrated to play crucial regulatory roles for self-renewal regulation of HSCs [21-24]. On the other hand, signals derived from BMP and TGF- $\beta$ pathways negatively regulate stem cell proliferation [13, 25-28]. Depending on the cellular context, cross-talk between BMP and Wnt signaling is critical for the proper cell fate decision of normal stem cells [13]. Tipping the delicate balance between positive and negative regulators of stem cell self-renewal in either direction can be problematic in vivo. For example, genetic changes leading to aberrant Wnt signaling in either stem cells or progenitors have been implicated as early events in the development of leukemia and other cancers [20].

The differentiation capacity of adult stem cells is normally restricted to specific cell lineages of the respective tissue type. However, adult stem cells have been observed to exhibit a certain level of cellular flexibility [29]. For instance, muscle derived stem cells have been shown to give rise to blood cells [30]. Cell fusion, albeit at a low frequency, has been suggested as one of the possible mechanisms underlying this phenomenon (reviewed in [8]). The limited plasticity of adult stem cells and other potential complications may largely restrict the clinical applications of adult stem cells in regenerative medicine. Nonetheless, these observations potentially have very important implications for cancer metastasis [12]. For example, cellular plasticity in stem cells may facilitate the epithelial to mesenchymal transition, which has been postulated as a key event during the early phase of cancer metastasis [31].

\section{Discovery and properties of CSCs}

With the landmark work accomplished by John Dick and his co-workers in human leukemia studies, recent years have witnessed the exciting discoveries of CSCs in solid tumors, including those of the breast and the brain [32-36]. Several excellent reviews have covered the supporting evidence and implications of CSCs for carcinogenesis [37-40]. Applying principles established from stem cell research, human CSCs are functionally defined by their enriched capacity to regenerate cancers using xenograft mouse models. Similar to normal stem cells, CSCs can reproduce themselves through the process of self-renewal, which can be studied in serial transplantation assays. Additionally, cancers derived from purified CSCs recapitulate the heterogeneous phenotypes of the parental cancer from

Table 1 Summary of reported human (i) or mouse (ii) cell surface makers for normal or malignant tissue stem cells

\begin{tabular}{|c|c|c|}
\hline Organ & Normal stem cell markers & Cancer stem cell markers \\
\hline \multirow[t]{2}{*}{ Hematopoietic } & (i) $\left.\mathrm{CD} 34^{+} \mathrm{CD} 38^{-} \mathrm{Thy}^{-} \mathrm{Lin}^{-} 130-133\right]$ & (i) $\mathrm{CD} 34^{+} \mathrm{CD} 38^{-} \mathrm{Thy} 1^{-} \operatorname{Lin}^{-}[32,47]$ \\
\hline & (ii) $\mathrm{c}-\mathrm{Kit}^{+} \mathrm{Thy} 1^{\text {low }} \mathrm{Scal}^{+} \operatorname{Lin}^{-}[134,135]$ & \\
\hline Breast & (ii) $\mathrm{CD} 29^{\mathrm{hi}} \mathrm{CD} 24^{+} \operatorname{Lin}^{-}[7]$ & \\
\hline Brain & (i) $\mathrm{CD}_{133}{ }^{+} \operatorname{Lin}^{-}[41]$ & (i) $\mathrm{CD}_{133^{+}}[34-36]$ \\
\hline Prostate & (i) $\mathrm{CD} 133^{+} \mathrm{a} 2 \mathrm{~b} 1^{\mathrm{hi}}[138]$ & (i) $\mathrm{CD}_{4} 4^{+} \alpha 2 \beta 1^{\mathrm{hi}} \mathrm{CD} 133^{+}[139]$ \\
\hline
\end{tabular}


which they were derived, reflecting the differentiation capacity of CSCs $[32,33]$. These observations suggest that CSCs contain the complete genetic programs necessary to initiate and sustain tumor growth. The demonstration of CSCs in solid tumors, however, has not been reproduced in a large number of independent research groups and still awaits further validation.

As shown in Table 1, surface markers have been used to describe CSCs from different cancers. Interestingly, cell surface phenotypes for leukemia stem cells $\left(\mathrm{CD} 34^{+} \mathrm{CD} 38^{-}\right)$ are virtually identical to normal HSCs. Similarly, CD133, which is a marker for normal neural stem cells, has also been used to enrich for brain tumor stem cells [35, 41]. Although they share many molecular pathways with normal stem cells, it is not surprising that CSCs have their own distinguishing molecular profiles. For example, the Bmi-1 proto-oncogene plays an essential role in the regulation of self-renewal for both leukemia stem cells as well as HSCs $[42,43]$. Bmi-1 is also required for neural stem cell selfrenewal and is highly expressed in brain tumor CSCs [35, $44,45]$. In contrast, loss of the PTEN tumor suppressor functionally distinguishes leukemia stem cells from normal HSCs [46]. In the future, identifying and characterizing unique features of CSCs that discriminate them from normal stem cells will be pivotal for devising specific therapies that would spare normal stem cells. Additionally, an understanding of the origin of CSCs may provide stronger diagnostic and therapeutic power to clinicians.

\section{Origins of CSCs}

The discovery of CSCs begs the question regarding the origin of these cells. Are they derived from normal stem cells with a cancerous phenotype? Or do previously differentiated progenitor cells with oncogenic mutations regain the ability to self-renew? A third theory hypothesizes that CSCs may come from a rare fusion event between stem cells and other cells. Normal stem cells may be ideal target cells for accumulating mutations that are necessary for stepwise malignant transformation due to their inherent self-renewal capacity. Since multiple pathways are involved in self-renewal of stem cells, it seems conceptually more difficult for a differentiated cell to regain this ability through mutations. But the rareness of stem cells in tissues may counter this theory because of the low probability that they could be targeted by mutations. The relative abundance of transient amplifying immediate progenitor cells, derived from stem cells retaining partial self-renewal capacity, makes them likely candidates for initial transforming events. As documented below, evidence exists for both the stem cell and the committed progenitor as the origin of CSCs.
Similarity in cell surface markers suggests that normal tissue stem cells may be the targets of oncogenic transformation and give rise to CSCs (see Table 1). Expansion of mammary stem cells in mouse breast cancer models prior to cancer development is also indicative of a potential connection between normal tissue stem cells and CSCs [6]. Similar observations were made in other cancer models [5, 47]. However, the mere expansion of a normal stem cell in a tumor is not sufficient to justify the conclusion that it is the cell of origin for tumors. A more direct proof was shown by the fact that the ectopic expression of both Met and Myc oncogenes in MESCs/progenitors was sufficient to drive breast cancer development, although the identity of the initial cell population needs to be characterized better [48]. Moreover, bone marrow derived cells (BMDCs) have been shown to initiate a gastric intraepithelial neoplasia that proceeds to gastric adenocarcinoma after chronic $\mathrm{He}$ licobacter infection [49]. In this study, mesenchymal stem cells from bone marrow have been proposed as candidate cells that give rise to gastric cancer. However, definitive experimental evidence showing normal tissue stem cells as origins for CSCs remains to be established.

Several stronger lines of evidence support the notion that a committed progenitor can be the cancer-initiating cell as a result of oncogenic transformation. Co-expression of $\mathrm{Bcl}-2$ and the $\mathrm{BCR} / \mathrm{ABL}$ protein (the fusion protein found in $\sim 90 \%$ of CML patients) in committed myeloid progenitors is sufficient to drive leukemia development in mice [50]. Leukemic granulocyte-macrophage progenitors have been shown to be able to self-renew through the activation of the Wnt/ $\beta$-catenin signaling pathway [51]. More recently, the MLL-AF9 fusion protein has been shown to transform committed granulocyte-macrophage progenitors into leukemia stem cells. Reactivation of a subset of signature genes expressed in HSCs correlates with regaining of an enhanced self-renewal capacity [52]. Researches in brain tumor development also indicate that more committed neural progenitor cells are likely to be the targets of tumorigenic mutations [53].

Although no direct experimental evidence is currently available for the cell fusion origin of CSCs, as mentioned above, cell fusion has been shown to be one of the mechanisms for the apparent cellular plasticity associated with tissue stem cells [8]. However, it is not clear from previous studies whether stem cells themselves are fused with other cell types in different tissues in vivo. Conceptually, cell fusion between stem cells and mutated cells might lead to regaining of self-renewal capacity to allow further accumulation of transforming mutations. A recent study has shown that BMDCs were able to fuse to neoplastic epithelium [54]. Additionally, the fusogenic factor CD44 is used as a positive surface marker for CSCs in breast cancer 
implying that these cells may have the capacity to fuse with other cell types. If cell fusion is an origin of CSCs, it could easily explain the detection of both fusogenic proteins and aneuploid cells commonly associated with neoplastic malignances [55].

While future studies are certainly needed to provide definitive proof for identifying the origin of CSCs, it is important to remember that demonstrating one model for the formation of CSCs in a given system does not necessarily exclude other mechanisms. The possible origins for CSCs are not mutually exclusive. For example, it has been shown that loss of Ink $4 a$ and $A r f$ expression combined with EGFR activation can cause de-differentiation of astrocytes as well as the transformation of neural stem cells, both of which result in a similar high grade malignant glioma [56]. Regardless of their origin, CSCs may play a critical role in metastasis because of their potential to migrate into different tissues. Additionally, CSCs from different origins may possess different metastasis abilities. Although comparatively less is known about the governing of mCSC migration, well-characterized evidence has elucidated the role that the niche plays in regulating normal stem cell migration.

\section{Stem cell niche and tumor migration}

In 1978, Schofield suggested that stem cells live in a niche, i.e. a physiologically defined supportive microenvironment, as demonstrated through early co-culture and transplantation studies [57]. Recently, significant progress has been made in characterizing the in vivo architecture and functions of stem cell niches in different model systems including Caenorhabditis elegans, Drosophila and mammals $[13,58,59]$. Niches for germ line stem cells (GSCs) in the Drosophila ovary or testis have been well characterized with great anatomic detail using genetic and cell biological approaches $[60,61]$. Critical signaling molecules that govern the self-renewal and differentiation of Drosophila GSCs, including activators of the BMP pathway and JakStat signaling, are derived from the niche [62-66]. One mechanism through which niche factors can modulate stem cell fate decision is the control of symmetric (producing two identical daughter cells) versus asymmetric (producing one identical and one differentiated cell) division [67].

In mammals, niches for adult stem cells have been characterized in the bone marrow, skin/hair follicle, intestine, neural system and testis [59]. Cell types and architectures of niches for specific stem cells are variable from tissue to tissue. Nonetheless, many key players in stem cell niches have evolutionally conserved functions in both normal and malignant tissues, and thus may play key roles in tumorigenesis and metastasis to different target organs.
For example, BMPs and their antagonists are known to play a crucial role in stem and progenitor cell biology as regulators of the balance between expansion and differentiation. BMPs promote differentiation of stem cells, thus promoting exit from the stem cell compartment. Gremlin 1 , a secreted antagonist of the BMP pathway, was found to be overexpressed in tumor stromal cells derived from basal cell carcinoma (BCC), but not in those derived from nontumor skin [111]. BMP inhibits and Gremlin 1 promotes proliferation of cultured $\mathrm{BCC}$ cells. Thus, factors secreted by tumor stroma may influence the stem cell niche of the tumor microenvironment, providing a suitable milieu for cancer development.

Potentially related to cancer metastasis, one critical function of the niche is to serve as an anchoring site for stem cells. For instance, HSCs are physically attached to their osteoblastic niche cell $\left(\mathrm{N}\right.$-cadherin $\left.{ }^{+} / \mathrm{CD}^{-} 5^{-}\right)$in the bone through a membrane bound $N$-cadherin $/ \beta$-catenin complex $[68,69]$. It is noteworthy that $\beta$-catenin is a key downstream mediator of the canonical Wnt signaling pathway, which is essential for self-renewal of stem cells. Retention of $\beta$ catenin at the stem cell membrane may prevent precocious activation of the Wnt signaling pathway [20]. Osteopontin (Opn), a glycoprotein that negatively regulates the pool size of HSCs in bone marrow, is also critical for breast cancer bone metastasis [70-73]. Other critical adhesion molecules required for stem cell localization include integrins [74-79].

With respect to HSCs, two distinct niches have been defined. The first is the endosteal bone surface niche, which is composed primarily of osteoblasts and correlates positively with the pool size of HSCs $[68,69,80,81]$. An alternative vascular niche for HSCs composed of endothelial cells has recently been identified in both the bone marrow and the spleen $[82,83]$. Similar to the loss of the osteoblastic niche, depletion of endothelial cells in vivo also leads to diminished HSC activity and resulting hematopoietic failure [84]. Why then are there two distinct niches for the same HSC cells? Supported by several experimental observations, an attractive hypothesis proposes that the osteoblastic niche functions primarily in maintaining HSC quiescence, whereas the vascular niche promotes HSC proliferation, differentiation and migration [85].

By far the most detailed knowledge concerning normal stem cell migration comes from the hematopoietic system. Intriguingly, many of the factors known to govern HSC migration are also critical mediators of cancer metastasis. Under normal physiological conditions, small numbers of HSCs are found in the bloodstream. In response to mobilizing agents such as G-CSF and signaling through the laminin receptor, increased numbers of HSCs circulate out of the bone marrow [86]. The laminin receptor has 
also been shown to play a key role in cancer metastasis [87]. Similarly, stromal cell derived factor and its receptor CXCR4 form a critical regulatory axis for HSC migration, engraftment and homing [88-92], and also function in the metastasis of breast, prostate and other types of cancer [73, 93-100]. Matrix metalloproteinase-9 (MMP-9), belongs to a family of MMPs that plays a critical role during cancer cell invasion [101-104], and it is also involved in HSC homing and migration [105-107]. In addition to providing niches for HSCs, skeletal bones are also the most common sites for cancer metastasis [108]. It has been shown that HSCs lacking a calcium sensing receptor $(\mathrm{CaR})$ are unable to localize to the endosteal niche in the bone [109]. Elevated CaR expression in primary breast cancer samples correlates positively with bone metastasis [110]. Therefore, bone-specific factors such as the level of calcium ions may serve as chemo-attractants for guiding the migrating cancer cells into the bone. These striking similarities that connect normal stem cells to metastatic cancer cells raise the question of what role CSCs may play in cancer metastasis.

\section{CSCs and metastasis}

Metastasis is a complex, multi-step process. Tissue tropisms associated with cancer metastasis indicate that specific and distinct cellular and molecular mechanisms are involved. The prevailing clonal selection model of metastasis contends that genetic mutations attained late in tumorigenesis provide a selective advantage for cells to metastasize. However, recent studies now lend their support to the notion that metastasis capacity is pre-determined by genetic changes acquired at the initial stages of tumor development [112]. Applying genomic approaches, molecular signatures have been defined to successfully predict poor prognosis for patients due to the metastatic potential of solid tumors. This suggests that the metastasis gene program is shared by the majority of cancer cells found in primary tumors [113-116]. Presently, the functional relevance of those signature genes to the underlying mechanisms for cancer progression and metastasis is not immediately obvious, partially due to the lack of significant overlap among reported signatures. Furthermore, these studies did not address the lingering questions regarding what factors govern the tissue tropism for a given cancer, which has been observed for over one hundred years [117]. Fortunately, functional genomic studies have begun to shed light on the cellular and molecular mechanisms of tissue-specific metastasis [73, 118-120]. Results from these studies have shown that a minor population of cancer cells within a heterogeneous breast tumor is already programmed to preferentially metastasize to specific organs. The molecular signatures of these tissue-specific metastatic cells can be distinguished from the general poor prognosis signatures. Nevertheless, it remains to be determined if the defining signature of tissue specific metastasis overlaps with the expression profile of CSCs. If an overlap exists, is there a subset of the gene profile responsible for determining the different tissue tropisms during metastasis? Part of the answer to this question likely involves the interactions between CSCs and their microenvironments.

Major clues as to the relation of niche formation and metastasis came from a recent study by Kaplan et al. [121], which characterized the initiation of the pre-metastasis niche by BMDCs after implantation of lung cancer or melanoma cells. In this study, it was shown that BMDCs are directed to the future sites of metastasis prior to cancer cell arrival by secreted factors in the cancer cell conditioned media. In addition, blocking the availability of the pre-metastasis niche components largely eliminated cancer metastasis, potentially indicating the functional importance of the pre-metastasis niche. The recruitment of BMDCs to the pre-metastasis niche could involve the extracellular matrix protein Opn. As mentioned above, Opn is a secreted protein known to play a role in metastasis of many tumors $[72,114]$. It has been shown to be overexpressed in subpopulations of highly bone-metastatic breast cancer cells from the MDA-MB-231 cell line. When co-overexpressed with IL-11, it induces normally non-metastatic cells to metastasize [73]. One of the natural ligands for Opn is the $\alpha 4 \beta 1$ integrin complex, a heterodimer expressed on the surface of the recruited BMDCs in the Kaplan study. Putting these observations together, one can envision a scenario whereby tumor cells secrete factors such as Opn, which aid in recruiting BMDCs to the future sites of metastasis where they restructure the local microenvironment, making it amenable to the growth of metastatic cells. Although it remains an open question whether only CSCs are responsible for orchestrating the formation of the pre-metastasis niche, it is clear that the tumor cells are able to secrete as yet undetermined factors that can localize and initiate the pre-metastasis niche through unknown mechanisms. This study represents an important conceptual advance; it shows that incoming metastatic cells are capable of remodeling the microenvironment at preferred sites into a more permissive/supportive location.

Several characteristics of CSCs make them likely candidates to occupy and thrive in these foreign sites. First, it is theoretically possible that only CSCs within tumors have the ability to initiate and sustain cancer growth. It has been known for years that just one cell can initiate a metastatic lesion [122]. Therefore, even if non-CSCs migrate (which is likely, given the number of cancer cells that can be detected in the blood), they would not be able to propagate into heterogeneously diverse metastatic lesions. 


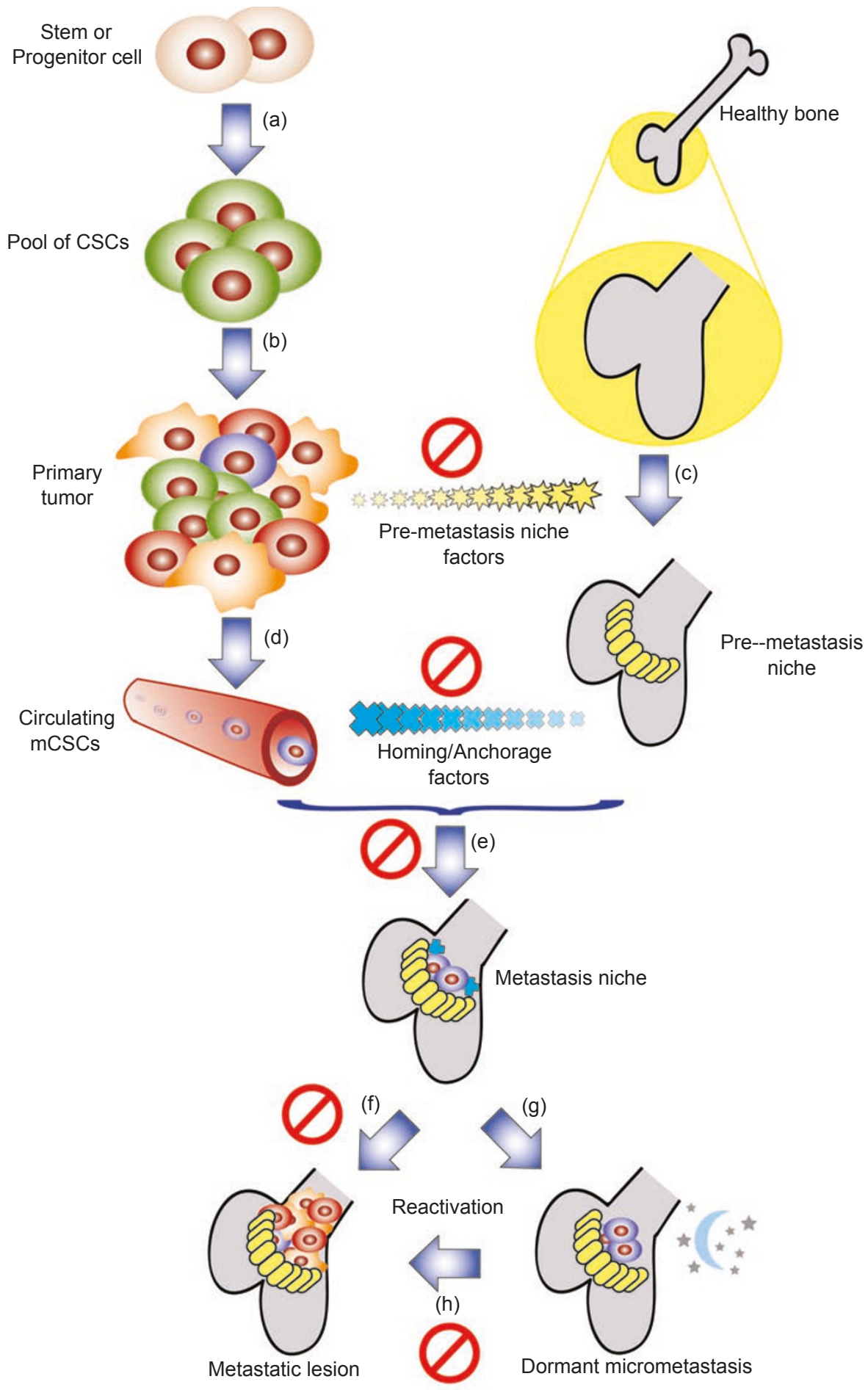

Figure 1 A model for tissue-specific metastasis mediated by mCSCs. Irrespective of the cell of origin, the first step of this model is a transformation event (a) after which the self-renewal capacity leads to an expansion of the CSC pool. This pool of tumor-initiating cells has the capacity to expand into a fully heterogenous primary tumor mass (b). Secretion of pre-metastasis niche forming factors (c) plays a critical role in determining the tissue tropism of the future metastatic lesion. Once the mCSCs begin to migrate through the blood (d), they are guided by homing and anchorage factors produced by the niche (e). After seeding, the local microenviroment in the niche helps determine if the mCSCs will either proliferate into a metastatic lesion directly (f), or will enter a quiescent period (g), which can be cut short by reactivation signals (h) that promote expansion into a full blown metastatic lesion. These key steps of metastasis present several potential targets for therapeutic interventions. $\oslash=$ Potential therapeutic intervention 
Furthermore, the inherent plasticity of stem cells makes them more adept to survive in a foreign environment (albeit primed by the pre-metastasis niche) where growth factors and other signaling molecules are different than in the primary tumor site. Increased genetic instability in CSCs is also likely to provide a selective advantage in adapting to foreign sites. However, it remains to be seen whether all CSCs are equally capable of forming metastasis at different sites. Formation of organ-specific metastases may require both the CSCs property and the ability of either the $\mathrm{mC}$ SCs or their progenies to adapt to a particular target tissue microenvironment. Tumor-initiating capacity is required at any metastasis site along with a niche for it. However, the immediate progeny of mCSCs may soon succumb unless they have an ability to exploit that environment. In other words, CSCs may be necessary to re-initiate the tumor in the strange new environment at metastasis sites, but they will be insufficient to maintain metastatic growth if their progeny cannot survive owing to a lack of organ-specific adaptability.

In light of significant advances in metastasis and stem cell research, we propose a CSC-based model for both tumorigenesis and metastasis (depicted in Figure 1). Initial transforming events could occur either in adult stem cells, their more differentiated progenies or fused cells to give rise to CSCs. Gain of self-renewal capacity at early phases of cancer is essential for further accumulation of oncogenic transformations and eventual development of cancer. During the establishment of the CSC pool, CSCs inherit a unique set of genetic and/or epigenetic changes that determine the cancer malignancy, metastatic potential and the tissue tropism. The initial origin of CSCs may influence the phenotypes of developing cancer, including the metastatic property. Molecular crosstalk between the primary tumor and the pre-metastasis niche through secreted stimulatory signals helps govern the homing of mCSCs. Trafficking towards preferred tissues and organs of mCSCs is guided by cues such as oxygen gradients or other chemo-attractants derived from niche sites [94, 123-125].

CSCs and mCSCs at primary and secondary sites can either hijack the niches for normal stem cells or recruit new components to form a permissive niche. The availability of niche components and the influence of other factors such as immune surveillance also contribute to primary tumor and metastasis development. mCSCs may then either actively proliferate at the new site or stay dormant, similar to the quiescent state of normal stem cells. Stimulatory factors from the niche can lead to reactivation of the CSCs and formation of a metastatic lesion, which may partly explain temporal patterns of primary tumors versus secondary tumors, although this remains to be determined. Since only a few mCSCs would need to leave the primary tumor site to initiate metastasis, this could help reconcile the observation that cancer cells can be detected in distant sites long before any detectable dissemination occurs at the primary tumors. mCSCs at metastatic sites maintain most of the genetic programs acquired at the primary tumor site through self-renewal, which explains the phenotypic similarities between primary and metastatic cancers. However, mCSCs in secondary sites are able to evolve independently by accumulating additional genetic alterations that render them resistant to treatments that are effective against primary tumors.

\section{Implication of CSCs for metastasis therapy}

If $\mathrm{mCSCs}$ are proven to be critical for metastasis, they will have highly significant implications in the realm of cancer treatment. Our model predicts that preventative treatment for metastasis should be applied significantly earlier than current practices. The fact that stem cells rarely divide and have other cellular properties distinct from the rest of tumor population, coupled with the observation that they may have high levels of drug transporters to pump chemotherapy agents out of the cell, has led many to believe that traditional chemo- or radiation therapies are not sufficient to clear these tumor initiating cells from the body. A recent study in glioma has provided concrete evidence for the ability of CSCs to contribute to radioresistance through preferential activation of the DNA damage checkpoint response and an increase in DNA repair capacity [126]. Therefore, targeted therapies to eliminate CSCs and mCSCs could lead to a revolution in the way cancer is treated. A few possible mechanisms to target these cells are presented below and highlighted in Figure 1.

\section{Self-renewal and differentiation}

If proliferation of CSCs is important for the growth of the primary tumor as well as progression to metastatic disease, one obvious target for eliminating these cells is to hamper their self-renewal capacity. Previously developed therapies such as cyclopamine (targeting the hedgehog signaling) and exisulind, bromoindirubin-3'-oxime, and imatinib (targeting the $\mathrm{Wnt} / \beta$-catenin pathways) have looked to inhibit self-renewal pathways likely critical to CSCs with varying levels of success (for a more detailed review, see [127]). By forcing CSCs to differentiate, their ability to self-renew would indirectly be eliminated. One of the most successful (and general) differentiation inducers to be used in clinical practice has been all trans-retinoic acid for patients with acute premyelocytic leukemia. Other general inducers such as TPA, DMSO, butyric acid and vitamin $\mathrm{D}_{3}$ have also been tried for solid tumors; however, using targeted therapies such as nerve growth factors, PPAR $\alpha$ activators 
or compounds such as vesnarinone may be more successful (see [128] for a review). Better functional characterization of CSC self-renewal and differentiation will translate into more targeted therapies compared to this first round of general differentiation inducers.

\section{Drug transporters}

Another clinically relevant inherent property of stem cells is their ability to pump drugs out of the cell through the use of the $\mathrm{ABC}$ family of drug transporters. If these efflux pumps could be inhibited, CSCs could be more susceptible to current or newly designed chemotherapeutic agents used in conjunction. Previous attempts to inhibit the ABCB1 transporter resulted in limited clinical success, but a new wave of ABCG2 specific inhibitors may lead to better results [129].

\section{Homing/seeding}

If mCSCs are highly mobile and able to generate metastases, then targeting the homing or seeding of these cells in the potential metastatic niches at the initial time of tumor presentation could significantly inhibit disease progression. In fact, blocking the homing factor CXCR4 has been shown to effectively prevent both primary tumor formation as well as metastasis in animal models [97]. Identification and characterization of niches for MCSCs will be helpful in identifying new targets for blocking the seeding of mCSCs. Furthermore, characterizing the secreted factors that set up the pre-metastasis niche could provide both diagnostic as well as therapeutic benefits.

\section{Reactivation}

Targeting homing and seeding of mCSCs may be technically difficult because by the time of tumor presentation, mCSCs or secreted factors may have already migrated to set up the pre-metastasis niche. Therefore, another potential clinical target would be to block the reactivation of dormant mCSCs at the metastatic sites. Therapies based on this idea are far off since the dormancy model needs to be validated and characterized before picking targets for drug therapy. Insights into the organization of the mCSC niche will provide clues as to the pathways associated with reactivation.

\section{Cautions}

With all of the previously mentioned therapeutic targets, there are two important caveats that must be considered. First, many of the molecular mechanisms that govern normal stem cell function also govern CSC function. Therefore, agents to target these pathways could have harmful effects on the homeostatic function of normal stem cells. As yet, it is unknown whether or not the increased proliferation of CSCs could provide a therapeutic window whereby a drug would more likely target CSCs over normal stem cells. Better discrimination between normal stem cells and CSCs will likely provide for targeted therapeutics. For instance, differential dependency on PTEN function of leukemia initiating cells versus HSCs will be useful in discovering specific therapeutic targets [46]. The precise degree of discrimination that is needed between normal and CSCs is likely to vary from system to system as targeting mammary or prostate stem cells, in addition to their cancerous counterparts, would not be detrimental to patients willing to undergo a mastectomy or prostatectomy. The second caveat to consider is that the current standard of measuring the therapeutic benefit of a potential therapy (i.e. the amount the drug can shrink a tumor) is potentially problematic for CSC specific therapies. As the CSC population is a minority population within the whole tumor, administration of agents to eliminate them alone, or in combination with conventional chemotherapies, will most likely not shrink the primary tumor to a significant degree. Studies to evaluate the effectiveness of these treatments should instead look for decreased reoccurrence or metastasis formation as a measure of drug effectiveness. While a number of drugs that may have unintentionally targeted CSCs have had limited success, future experiments to better understand the origin and function of CSCs in primary tumorigenesis and, especially, metastasis may lead to a new wave of therapeutic agents with the potential to go beyond the traditional way cancer is viewed and treated.

\section{Acknowledgment}

We thank members of our laboratories for the helpful discussion of this manuscript. We apologize to our colleagues whose important studies could not be cited directly here owing to space limitations. Our research was supported by American Cancer Society (RSG MGO-110765), Department of Defense (BC051647), Susan G Komen Foundation (BCTR0503765), New Jersey Commission on Cancer Research (05-2408-CCR-E0), National Cancer Institute, the WM Keck Foundation and the Kleberg Foundation.

\section{References}

1 Weigelt B, Peterse JL, van't Veer LJ. Breast cancer metastasis: markers and models. Nat Rev Cancer 2005; 5:591-602.

2 Hill RP. Identifying cancer stem cells in solid tumors: case not proven. Cancer Res 2006; 66:1891-1895.

3 Weissman IL. Stem cells: units of development, units of regeneration, and units in evolution. Cell 2000; 100:157-168.

4 Beltrami AP, Barlucchi L, Torella D, et al. Adult cardiac stem cells are multipotent and support myocardial regeneration. Cell 2003; 114:763-776.

5 Kim CF, Jackson EL, Woolfenden AE, et al. Identification of 
bronchioalveolar stem cells in normal lung and lung cancer. Cell 2005; 121:823-835.

6 Shackleton M, Vaillant F, Simpson KJ, et al. Generation of a functional mammary gland from a single stem cell. Nature 2006; 439:84-88.

7 Stingl J, Eirew P, Ricketson I, et al. Purification and unique properties of mammary epithelial stem cells. Nature 2006; 439:993-997.

8 Wagers AJ, Weissman IL. Plasticity of adult stem cells. Cell 2004; 116:639-648.

9 Goodell MA, Brose K, Paradis G, Conner AS, Mulligan RC. Isolation and functional properties of murine hematopoietic stem cells that are replicating in vivo. J Exp Med 1996; 183:17971806.

10 Cheng T, Rodrigues N, Shen H, et al. Hematopoietic stem cell quiescence maintained by $\mathrm{p} 21 \mathrm{cip} 1 /$ wafl. Science 2000 ; 287:1804-1808.

11 Yuan Y, Shen H, Franklin DS, Scadden DT, Cheng T. In vivo selfrenewing divisions of haematopoietic stem cells are increased in the absence of the early G1-phase inhibitor, p18INK4C. Nat Cell Biol 2004; 6:436-442.

12 McCulloch EA, Till JE. Perspectives on the properties of stem cells. Nat Med 2005; 11:1026-1028.

13 Moore KA, Lemischka IR. Stem cells and their niches. Science 2006; 311:1880-1885.

14 Gat U, DasGupta R, Degenstein L, Fuchs E. De novo hair follicle morphogenesis and hair tumors in mice expressing a truncated beta-catenin in skin. Cell 1998; 95:605-614.

15 Korinek V, Barker N, Moerer P, et al. Depletion of epithelial stem-cell compartments in the small intestine of mice lacking Tcf-4. Nat Genet 1998; 19:379-383.

16 Batlle E, Henderson JT, Beghtel H, et al. Beta-catenin and TCF mediate cell positioning in the intestinal epithelium by controlling the expression of EphB/ephrinB. Cell 2002; 111:251-263.

17 Kuhnert F, Davis CR, Wang HT, et al. Essential requirement for Wnt signaling in proliferation of adult small intestine and colon revealed by adenoviral expression of Dickkopf-1. Proc Natl Acad Sci USA 2004; 101:266-271.

18 Lo Celso C, Prowse DM, Watt FM. Transient activation of beta-catenin signalling in adult mouse epidermis is sufficient to induce new hair follicles but continuous activation is required to maintain hair follicle tumours. Development 2004; 131 :17871799.

19 Pinto D, Gregorieff A, Begthel H, Clevers H. Canonical Wnt signals are essential for homeostasis of the intestinal epithelium. Genes Dev 2003; 17:1709-1713.

20 Reya T, Clevers H. Wnt signalling in stem cells and cancer. Nature 2005; 434:843-850.

21 Reya T, Duncan AW, Ailles L, et al. A role for Wnt signalling in self-renewal of haematopoietic stem cells. Nature 2003; 423:409414.

22 Taipale J, Cooper MK, Maiti T, Beachy PA. Patched acts catalytically to suppress the activity of smoothened. Nature 2002; 418:892-897.

23 Varnum-Finney B, Xu L, Brashem-Stein C, et al. Pluripotent, cytokine-dependent, hematopoietic stem cells are immortalized by constitutive Notch1 signaling. Nat Med 2000; 6:1278-1281.

24 Willert K, Brown JD, Danenberg E, et al. Wnt proteins are lipidmodified and can act as stem cell growth factors. Nature 2003;
423:448-452.

25 Duncan AW, Rattis FM, DiMascio LN, et al. Integration of Notch and Wnt signaling in hematopoietic stem cell maintenance. Nat Immunol 2005; 6:314-322.

$26 \mathrm{He}$ XC, Zhang J, Tong WG, et al. BMP signaling inhibits intestinal stem cell self-renewal through suppression of Wnt-betacatenin signaling. Nat Genet 2004; 36:1117-1121.

27 Larsson J, Blank U, Helgadottir H, et al. TGF-beta signalingdeficient hematopoietic stem cells have normal self-renewal and regenerative ability in vivo despite increased proliferative capacity in vitro. Blood 2003; 102:3129-3135.

28 Li L, Neaves WB. Normal stem cells and cancer stem cells: the niche matters. Cancer Res 2006; 66:4553-4557.

29 Krause DS, Theise ND, Collector MI, et al. Multi-organ, multilineage engraftment by a single bone marrow-derived stem cell. Cell 2001; 105:369-377.

30 Jackson KA, Mi T, Goodell MA. Hematopoietic potential of stem cells isolated from murine skeletal muscle. Proc Natl Acad Sci USA 1999; 96:14482-14486.

31 Thiery JP. Epithelial-mesenchymal transitions in development and pathologies. Curr Opin Cell Biol 2003; 15:740-746.

32 Bonnet D, Dick JE. Human acute myeloid leukemia is organized as a hierarchy that originates from a primitive hematopoietic cell. Nat Med 1997; 3:730-737.

33 Al-Hajj M, Clarke MF. Self-renewal and solid tumor stem cells. Oncogene 2004; 23:7274-7282.

34 Singh SK, Clarke ID, Terasaki M, et al. Identification of a cancer stem cell in human brain tumors. Cancer Res 2003; 63:58215828 .

35 Hemmati HD, Nakano I, Lazareff JA, et al. Cancerous stem cells can arise from pediatric brain tumors. Proc Natl Acad Sci USA 2003; 100:15178-15183.

36 Singh SK, Hawkins C, Clarke ID, et al. Identification of human brain tumour initiating cells. Nature 2004; 432:396-401.

37 Clarke MF, Fuller M. Stem cells and cancer: two faces of eve. Cell 2006; 124:1111-1115.

38 Huntly BJ, Gilliland DG. Leukaemia stem cells and the evolution of cancer-stem-cell research. Nat Rev Cancer 2005; 5:311321.

39 Polyak K, Hahn WC. Roots and stems: stem cells in cancer. Nat Med 2006; 12:296-300.

40 Reya T, Morrison SJ, Clarke MF, Weissman IL. Stem cells, cancer, and cancer stem cells. Nature 2001; 414:105-111.

41 Uchida N, Buck DW, He D, et al. Direct isolation of human central nervous system stem cells. Proc Natl Acad Sci USA 2000; 97:14720-14725.

42 Lessard J, Sauvageau G. Bmi-1 determines the proliferative capacity of normal and leukaemic stem cells. Nature 2003; 423:255-260.

43 Park IK, Qian D, Kiel M, et al. Bmi-1 is required for maintenance of adult self-renewing haematopoietic stem cells. Nature 2003; 423:302-305.

44 Molofsky AV, Pardal R, Iwashita T, et al. Bmi-1 dependence distinguishes neural stem cell self-renewal from progenitor proliferation. Nature 2003; 425:962-967.

45 Liu S, Dontu G, Mantle ID, et al. Hedgehog signaling and Bmi-1 regulate self-renewal of normal and malignant human mammary stem cells. Cancer Res 2006; 66:6063-6071.

46 Yilmaz OH, Valdez R, Theisen BK, et al. Pten dependence dis- 
tinguishes haematopoietic stem cells from leukaemia-initiating cells. Nature 2006; 441:475-482.

47 Miyamoto T, Weissman IL, Akashi K. AML1/ETO-expressing nonleukemic stem cells in acute myelogenous leukemia with 8;21 chromosomal translocation. Proc Natl Acad Sci USA 2000; 97:7521-7526.

48 Welm AL, Kim S, Welm BE, Bishop JM. MET and MYC cooperate in mammary tumorigenesis. Proc Natl Acad Sci USA 2005; 102:4324-4329.

49 Houghton J, Stoicov C, Nomura S, et al. Gastric cancer originating from bone marrow-derived cells. Science 2004; 306:15681571.

50 Jaiswal S, Traver D, Miyamoto T, et al. Expression of BCR/ABL and BCL-2 in myeloid progenitors leads to myeloid leukemias. Proc Natl Acad Sci USA 2003; 100:10002-10007.

51 Jamieson CH, Ailles LE, Dylla SJ, et al. Granulocyte-macrophage progenitors as candidate leukemic stem cells in blast-crisis CML. N Engl J Med 2004; 351:657-667.

52 Krivtsov AV, Twomey D, Feng Z, et al. Transformation from committed progenitor to leukaemia stem cell initiated by MLLAF9. Nature 2006; 442:818-822.

53 Vescovi AL, Galli R, Reynolds BA. Brain tumour stem cells. Nat Rev Cancer 2006; 6:425-436.

54 Rizvi AZ, Swain JR, Davies PS, et al. Bone marrow-derived cells fuse with normal and transformed intestinal stem cells. ProcNatl Acad Sci USA 2006; 103:6321-6325.

55 Bjerkvig R, Tysnes BB, Aboody KS, Najbauer J, Terzis AJ. Opinion: the origin of the cancer stem cell: current controversies and new insights. Nat Rev Cancer 2005; 5:899-904.

56 Bachoo RM, Maher EA, Ligon KL, et al. Epidermal growth factor receptor and Ink4a/Arf: convergent mechanisms governing terminal differentiation and transformation along the neural stem cell to astrocyte axis. Cancer Cell 2002; 1:269-277.

57 Schofield R. The relationship between the spleen colony-forming cell and the haemopoietic stem cell. Blood Cells 1978; 4:7-25.

$58 \mathrm{Li} \mathrm{L}$, Xie T. Stem cell niche: structure and function. Annu Rev Cell Dev Biol 2005; 21:605-631.

59 Scadden DT. The stem-cell niche as an entity of action. Nature 2006; 441:1075-1079.

60 Xie T, Spradling AC. A niche maintaining germ line stem cells in the Drosophila ovary. Science 2000; 290:328-330.

61 Lin H. The stem-cell niche theory: lessons from flies. Nat Rev Genet 2002; 3:931-940.

62 Kiger AA, Jones DL, Schulz C, Rogers MB, Fuller MT. Stem cell self-renewal specified by JAK-STAT activation in response to a support cell cue. Science 2001; 294:2542-2545.

63 Schulz C, Kiger AA, Tazuke SI, et al. A misexpression screen reveals effects of bag-of-marbles and TGF beta class signaling on the Drosophila male germ-line stem cell lineage. Genetics 2004; 167:707-723.

64 Song X, Wong MD, Kawase E, et al. Bmp signals from niche cells directly repress transcription of a differentiation-promoting gene, bag of marbles, in germline stem cells in the Drosophila ovary. Development 2004; 131:1353-1364.

65 Tulina N, Matunis E. Control of stem cell self-renewal in Drosophila spermatogenesis by JAK-STAT signaling. Science 2001; 294:2546-2549.

66 Xie T, Spradling AC. Decapentaplegic is essential for the maintenance and division of germline stem cells in the Drosophila ovary. Cell 1998; 94:251-260.

67 Morrison SJ, Kimble J. Asymmetric and symmetric stem-cell divisions in development and cancer. Nature 2006; 441:10681074.

68 Calvi LM, Adams GB, Weibrecht KW, et al. Osteoblastic cells regulate the haematopoietic stem cell niche. Nature 2003; 425:841-846.

69 Zhang J, Niu C, Ye L, et al. Identification of the haematopoietic stem cell niche and control of the niche size. Nature 2003; 425:836-841.

70 Nilsson SK, Johnston HM, Whitty GA, et al. Osteopontin, a key component of the hematopoietic stem cell niche and regulator of primitive hematopoietic progenitor cells. Blood 2005; 106:12321239.

71 Stier S, Ko Y, Forkert R, et al. Osteopontin is a hematopoietic stem cell niche component that negatively regulates stem cell pool size. J Exp Med 2005; 201:1781-1791.

72 Furger KA, Menon RK, Tuck AB, Bramwell VH, Chambers AF. The functional and clinical roles of osteopontin in cancer and metastasis. Curr Mol Med 2001; 1:621-632.

73 Kang Y, Siegel PM, Shu W, et al. A multigenic program mediating breast cancer metastasis to bone. Cancer Cell 2003; 3:537-549.

74 Campos LS, Decker L, Taylor V, Skarnes W. Notch, epidermal growth factor receptor, and beta1-integrin pathways are coordinated in neural stem cells. J Biol Chem 2006; 281:5300-5309.

75 Fuchs E, Tumbar T, Guasch G. Socializing with the neighbors: stem cells and their niche. Cell 2004; 116:769-778.

76 Hirsch E, Iglesias A, Potocnik AJ, Hartmann U, Fassler R. Impaired migration but not differentiation of haematopoietic stem cells in the absence of beta1 integrins. Nature 1996; 380:171175 .

77 Kurata S, Okuyama T, Osada M, et al. p51/p63 controls subunit alpha3 of the major epidermis integrin anchoring the stem cells to the niche. J Biol Chem 2004; 279:50069-50077.

78 Watt FM, Hogan BL. Out of Eden: stem cells and their niches. Science 2000; 287:1427-1430.

79 Wilson A, Murphy MJ, Oskarsson T, et al. c-Myc controls the balance between hematopoietic stem cell self-renewal and differentiation. Genes Dev 2004; 18:2747-2763.

80 Arai F, Hirao A, Ohmura M, et al. Tie2/angiopoietin-1 signaling regulates hematopoietic stem cell quiescence in the bone marrow niche. Cell 2004; 118:149-161.

81 Visnjic D, Kalajzic Z, Rowe DW, et al. Hematopoiesis is severely altered in mice with an induced osteoblast deficiency. Blood 2004; 103:3258-3264.

82 Kiel MJ, Yilmaz OH, Iwashita T, et al. SLAM family receptors distinguish hematopoietic stem and progenitor cells and reveal endothelial niches for stem cells. Cell 2005; 121:1109-1121.

83 Wagers AJ. Stem cell grand SLAM. Cell 2005; 121:967-970.

84 Avecilla ST, Hattori K, Heissig B, et al. Chemokine-mediated interaction of hematopoietic progenitors with the bone marrow vascular niche is required for thrombopoiesis. Nat Med 2004; 10:64-71.

85 Yin T, Li L. The stem cell niches in bone. J Clin Invest 2006; 116:1195-1201.

86 Papayannopoulou T. Current mechanistic scenarios in hematopoietic stem/progenitor cell mobilization. Blood 2004; 103:15801585.

87 Selleri C, Ragno P, Ricci P, et al. The metastasis-associated 67 
$\mathrm{kDa}$ laminin receptor is involved in G-CSF-induced hematopoietic stem cell mobilization. Blood 2006; 108:2476-2484.

88 Aiuti A, Webb IJ, Bleul C, Springer T, Gutierrez-Ramos JC. The chemokine SDF-1 is a chemoattractant for human CD34+ hematopoietic progenitor cells and provides a new mechanism to explain the mobilization of CD34+ progenitors to peripheral blood. J Exp Med 1997; 185:111-120.

89 Broxmeyer HE, Orschell CM, Clapp DW, et al. Rapid mobilization of murine and human hematopoietic stem and progenitor cells with AMD3100, a CXCR4 antagonist. J Exp Med 2005; 201:1307-1318.

90 Lapidot T, Kollet O. The essential roles of the chemokine SDF-1 and its receptor CXCR4 in human stem cell homing and repopulation of transplanted immune-deficient NOD/SCID and NOD/SCID/B2m(null) mice. Leukemia 2002; 16:1992-2003.

91 Peled A, Petit I, Kollet O, et al. Dependence of human stem cell engraftment and repopulation of NOD/SCID mice on CXCR4. Science 1999; 283:845-848.

92 Wright DE, Bowman EP, Wagers AJ, Butcher EC, Weissman IL. Hematopoietic stem cells are uniquely selective in their migratory response to chemokines. J Exp Med 2002; 195:1145-1154.

93 Liotta LA. An attractive force in metastasis. Nature 2001; 410:2425.

94 Muller A, Homey B, Soto H, et al. Involvement of chemokine receptors in breast cancer metastasis. Nature 2001; 410:50-56.

95 Murphy PM. Chemokines and the molecular basis of cancer metastasis. N Engl J Med 2001; 345:833-835.

96 Fernandis AZ, Prasad A, Band H, Klosel R, Ganju RK. Regulation of CXCR4-mediated chemotaxis and chemoinvasion of breast cancer cells. Oncogene 2004; 23:157-167.

97 Smith MC, Luker KE, Garbow JR, et al. CXCR4 regulates growth of both primary and metastatic breast cancer. Cancer Res 2004; 64:8604-8612.

98 Bernards R. Cancer: cues for migration. Nature 2003; 425:247248.

99 Li YM, Pan Y, Wei Y, et al. Upregulation of CXCR4 is essential for HER2-mediated tumor metastasis. Cancer Cell 2004; 6:459469.

100Liang Z, Wu T, Lou H, et al. Inhibition of breast cancer metastasis by selective synthetic polypeptide against CXCR4. Cancer Res 2004; 64:4302-4308.

101 John A, Tuszynski G. The role of matrix metalloproteinases in tumor angiogenesis and tumor metastasis. Pathol Oncol Res 2001; 7:14-23.

102Rafii S, Lyden D, Benezra R, Hattori K, Heissig B. Vascular and haematopoietic stem cells: novel targets for anti-angiogenesis therapy? Nat Rev Cancer 2002; 2:826-835.

103 Pratap J, Javed A, Languino LR, et al. The Runx2 osteogenic transcription factor regulates matrix metalloproteinase 9 in bone metastatic cancer cells and controls cell invasion. Mol Cell Biol 2005; 25:8581-8591.

104Chinni SR, Sivalogan S, Dong Z, et al. CXCL12/CXCR4 signaling activates Akt-1 and MMP-9 expression in prostate cancer cells: the role of bone microenvironment-associated CXCL12. Prostate 2006; 66:32-48.

105Heissig B, Hattori K, Dias S, et al. Recruitment of stem and progenitor cells from the bone marrow niche requires MMP-9 mediated release of kit-ligand. Cell 2002; 109:625-637.

106Janowska-Wieczorek A, Marquez LA, Dobrowsky A, Ratajczak
MZ, Cabuhat ML. Differential MMP and TIMP production by human marrow and peripheral blood CD34(+) cells in response to chemokines. Exp Hematol 2000; 28:1274-1285.

107 Kollet O, Shivtiel S, Chen YQ, et al. HGF, SDF-1, and MMP-9 are involved in stress-induced human CD34+ stem cell recruitment to the liver. J Clin Invest 2003; 112:160-169.

108 Raubenheimer EJ, Noffke CE. Pathogenesis of bone metastasis: a review. J Oral Pathol Med 2006; 35:129-135.

109Adams GB, Chabner KT, Alley IR, et al. Stem cell engraftment at the endosteal niche is specified by the calcium-sensing receptor. Nature 2006; 439:599-603.

110 Mihai R, Stevens J, McKinney C, Ibrahim NB. Expression of the calcium receptor in human breast cancer - a potential new marker predicting the risk of bone metastases. Eur J Surg Oncol 2006; 32:511-515.

111 Sneddon JB, Zhen HH, Montgomery K, et al. Bone morphogenetic protein antagonist gremlin 1 is widely expressed by cancerassociated stromal cells and can promote tumor cell proliferation. Proc Natl Acad Sci USA 2006; 103:14842-14847.

112 Bernards R, Weinberg RA. A progression puzzle. Nature 2002; 418:823.

113 Gupta PB, Kuperwasser C, Brunet JP, et al. The melanocyte differentiation program predisposes to metastasis after neoplastic transformation. Nat Genet 2005; 37:1047-1054.

114 Ramaswamy S, Ross KN, Lander ES, Golub TR. A molecular signature of metastasis in primary solid tumors. Nat Genet 2003; 33:49-54.

115 Singh D, Febbo PG, Ross K, et al. Gene expression correlates of clinical prostate cancer behavior. Cancer Cell 2002; 1:203209.

116 van't Veer LJ, Dai H, van de Vijver MJ, et al. Gene expression profiling predicts clinical outcome of breast cancer. Nature 2002; 415:530-536.

117 Paget S. The distribution of secondary growths in cancer of the breast. 1889. Cancer Metastasis Rev 1989; 8:98-101.

118 Minn AJ, Gupta GP, Siegel PM, et al. Genes that mediate breast cancer metastasis to lung. Nature 2005; 436:518-524.

119 Minn AJ, Kang Y, Serganova I, et al. Distinct organ-specific metastatic potential of individual breast cancer cells and primary tumors. J Clin Invest 2005; 115:44-55.

$120 \mathrm{Kang}$ Y. Functional genomic analysis of cancer metastasis: biologic insights and clinical implications. Expert Rev Mol Diagn 2005; 5:385-395.

121 Kaplan RN, Riba RD, Zacharoulis S, et al. VEGFR1-positive haematopoietic bone marrow progenitors initiate the pre-metastatic niche. Nature 2005; 438:820-827.

122Fidler IJ, Talmadge JE. Evidence that intravenously derived murine pulmonary melanoma metastases can originate from the expansion of a single tumor cell. Cancer Res 1986; 46:51675171.

123 Griffiths EA, Pritchard SA, Welch IM, Price PM, West CM. Is the hypoxia-inducible factor pathway important in gastric cancer? Eur J Cancer 2005; 41:2792-2805

124Muller A, Sonkoly E, Eulert C, et al. Chemokine receptors in head and neck cancer: association with metastatic spread and regulation during chemotherapy. Int J Cancer 2006; 118:21472157.

125 Pathak SK, Sharma RA, Steward WP, et al. Oxidative stress and cyclooxygenase activity in prostate carcinogenesis: targets for 
chemopreventive strategies. Eur J Cancer 2005; 41:61-70.

126Bao S, Wu Q, McLendon RE, et al. Glioma stem cells promote radioresistance by preferential activation of the DNA damage response. Nature 2006

127 Galmozzi E, Facchetti F, La Porta CA. Cancer stem cells and therapeutic perspectives. Curr Med Chem 2006; 13:603-607.

128Kawamata H, Tachibana M, Fujimori T, Imai Y. Differentiation-inducing therapy for solid tumors. Curr Pharm Des 2006; 12:379-385.

129Dean M, Fojo T, Bates S. Tumour stem cells and drug resistance. Nat Rev Cancer 2005; 5:275-284.

130Baum CM, Weissman IL, Tsukamoto AS, Buckle AM, Peault B. Isolation of a candidate human hematopoietic stem-cell population. Proc Natl Acad Sci USA 1992; 89:2804-2808.

131 Terstappen LW, Huang S, Safford M, Lansdorp PM, Loken MR. Sequential generations of hematopoietic colonies derived from single nonlineage-committed CD34+CD38- progenitor cells. Blood 1991; 77:1218-1227.

132 Civin CI, Trischmann T, Kadan NS, et al. Highly purified CD34positive cells reconstitute hematopoiesis. J Clin Oncol 1996; 14:2224-2233.
133 Hao QL, Smogorzewska EM, Barsky LW, Crooks GM. In vitro identification of single CD34+CD38- cells with both lymphoid and myeloid potential. Blood 1998; 91:4145-4151.

134Uchida N, Weissman IL. Searching for hematopoietic stem cells: evidence that Thy-1.11o Lin-Sca-1+ cells are the only stem cells in C57BL/Ka-Thy-1.1 bone marrow. J Exp Med 1992; 175:175184.

135Ikuta K, Weissman IL. Evidence that hematopoietic stem cells express mouse c-kit but do not depend on steel factor for their generation. Proc Natl Acad Sci USA 1992; 89:1502-1506.

136Blanpain C, Fuchs E. Epidermal stem cells of the skin. Annu Rev Cell Dev Biol 2006; 22:339-373.

137Fang D, Nguyen TK, Leishear K, et al. A tumorigenic subpopulation with stem cell properties in melanomas. Cancer Research 2005; 65:9328-9337.

138Richardson GD, Robson CN, Lang SH, et al. CD133, a novel marker for human prostatic epithelial stem cells. J Cell Sci 2004; 117:3539-3545.

139Collins AT, Berry PA, Hyde C, Stower MJ, Maitland NJ. Prospective identification of tumorigenic prostate cancer stem cells. Cancer Res 2005; 65:10946-10951. 